Annals of International Medical and Dental Research

E-ISSN: 2395-2822 | P-ISSN: 2395-2814

Vol-8, Issue-1 | January-February 2022

DOI: $10.53339 /$ aimdr.2022.8.1.10

Page no- 69-80 | Section- Research Article (Oral \& Maxillofacial Surgery)

\title{
Cervical Necrotizing Fasciitis: An Uncommon Fulminant Disease Entity
}

\author{
Manish Kumar Sharma ${ }^{1}$, Archna Sharma ${ }^{2 *}$
}

1Former Resident Department of Oral \& Maxillofacial Surgery, HPGDC, Shimla, Himachal Pradesh, India. Email: manishsharmamfos@gmail.com, Orcid ID: 0000 000217223118

${ }^{2}$ Former Resident, Department of Anaesthesia, IGMC, Shimla, Himachal Pradesh, India. Email: drarchanasharma1991@gmail.com, Orcid ID: 0000-00026860-4009

${ }^{*}$ Corresponding author

Received: 13 October 2021

Revised: 01 November 2021

Accepted: 11 November 2021

Published: 22 December 2021

Keywords:- Cervical necrotizing fasciitis, Fulminant infection, Odontogenic infection, Neck, Surgical debridement.

\section{INTRODUCTION}

Necrotizing fasciitis is a rare, fulminant, lifethreatening, single or polymicrobial infection of the soft connective tissue that spreads along the fascial planes. The disease is characterized by necrosis of the subcutaneous tissues and fasciae. Initially, the underlying muscles and overlying skin are spared but as the disease progress necrosis of the muscles and skin due to thrombosis of the feeding vessels may also take place. Necrotizing fasciitis is a rare disease which can affect any part of the body but commonly involves abdomen, perineum and limbs while involvement of the cervical region is rare. In case of cervical necrotizing fasciitis, infection usually spreads from odontogenic or pharyngeal source. If not diagnosed and treated at the earliest, necrotizing fasciitis may cause high systemic toxicity and compromise the general state of health of the patient.
Necrotizing fasciitis has high mortality and morbidity rate. Cervical necrotizing fasciitis has a particularly high mortality rate due to the proximity to many vital anatomical structures. Mortality rate may vary from $40 \%$ to $76 \%$.[1,2]

Hippocrates described the condition in the fifth century. Baurienne in the year 1764 first reported this infection affecting the perineum region of the patient. In the year 1883, Fournier described this infection in perineum region in five young adult patients and was later known as Fournier's gangrene. Joseph Jones (army surgeon) described this infection during the American civil war in the year 1871 as hospital gangrene. In the year 1918, Pfanner described the disease as necrotizing erysipelas. Meleney in the year 1924 identified haemolytic streptococci as causative agent and called the disease as streptococcal gangrene which was later named as Meleney's gangrene. Other 
Annals of International Medical and Dental Research

E-ISSN: 2395-2822 | P-ISSN: 2395-2814

Vol-8, Issue-1 | January-February 2022

DOI: $10.53339 /$ aimdr.2022.8.1.10

Page no- 69-80 | Section- Research Article (Oral \& Maxillofacial Surgery)

synonyms of the disease were malignant ulcer, gangrenous ulcer, phagedenis ulcer, phagedena gangaenosa, haemolytic streptococcal gangrene, synergistic necrotizing cellulitis, gangrenous erysipelas, necrotizing erysipelas and Meleney's synergistic gangrene. $[3,4]$

The term necrotizing fasciitis was first used by Wilson in the year 1952 and suggested the role of mixed flora in its pathogenesis. Disease is usually polymicrobial in origin. Causative organism includes haemolytic group A Streptococci, Staphylococci along with facultative anaerobes like Prevotella and Peptostreptococci etc. These virulent bacteria, alone or in synergistic combination, produce a severe necrotizing infection of the fasciae and soft tissues.[5,6]

The disease initially manifests as tender, edematous and erythematous overlying skin. As the underlying necrosis progresses, skin becomes pale and eventually turns dusky. Soft tissue crepitance due to the presence of subcutaneous gas may be a reliable physical indicator. Bullae formation, sloughing and foul smelling dish water exudate can also be observed. Spread of infection from cervical region into thorax may occur along carotid sheath, paratracheal fascia, retropharyngeal space or prevertebral fascia. Complications include airway obstruction, carotid artery occlusion, jugular venous thrombosis, mediastinitis, empyema, pneomonitis, pleural or pericardial effusion. Prompt diagnosis and identification, early aggressive surgical debridement and supportive broad spectrum antibiotic therapy are important factors for good prognosis. [7]

\section{CASE REPORT}

A forty-five year old male patient presented in the institution with the chief complaint of pain and swelling in the right submandibular region since 10 days. Patient gave a history of hot fomentation and use of local traditional ointments. Swelling increased rapidly involving entire right side of neck. Intra oral examination revealed no carious tooth or gingival infection. The location of the swelling was in the beard region pointing towards a possibility of furuncle as the source of infection. Patient had no history of any debilitating condition or immunocompromised state and was not taking medication for any systemic condition. Patient was febrile with no difficulty in breathing and swallowing. Local examination revealed diffuse swelling in the right submandibular region, extending on the neck. Overlying skin was erythematous on the periphery and was dark and dusky on the central region of the lesion. There was crepitus on palpation. USG and lab investigations were done in a tertiary care centre. Plain $X$ ray of the neck revealed the presence of air in the soft tissues. Lab investigations revealed leukocytosis, higher Creactive protein level and anaemia. Pus was collected and sent for culture and sensitivity. Empirical broad spectrum antibiotics were initiated and intra venous fluids were administered. The culture and sensitivity report showed growth of gram positive and gram negative rods sensitive to third generation cephalosporin ceftriaxone. Patient refused to general anaesthesia so incision and drainage was done under local anaesthesia. On removing the blackened overlying skin, dirty yellow foul smelling fascia was visible. The 
Annals of International Medical and Dental Research E-ISSN: 2395-2822 | P-ISSN: 2395-2814 Vol-8, Issue-1 | January-February 2022 DOI: $10.53339 /$ aimdr.2022.8.1.10 Page no- 69-80 | Section- Research Article (Oral \& Maxillofacial Surgery)

necrosed skin and fascia was excised and dressing with chlorhexidine gauze and chloramphenicol powder was done [Figure 1]. Necrosis spread inferiorly towards clavicular region. Serial debridement of the wound and excision of the necrosed fascia was done till there was evidence of fresh bleeding from skin edges and all the necrotic tissue was removed. Copious irrigation was done with povidone iodine, normal saline and $\mathrm{H} 2 \mathrm{O} 2$ four hourly

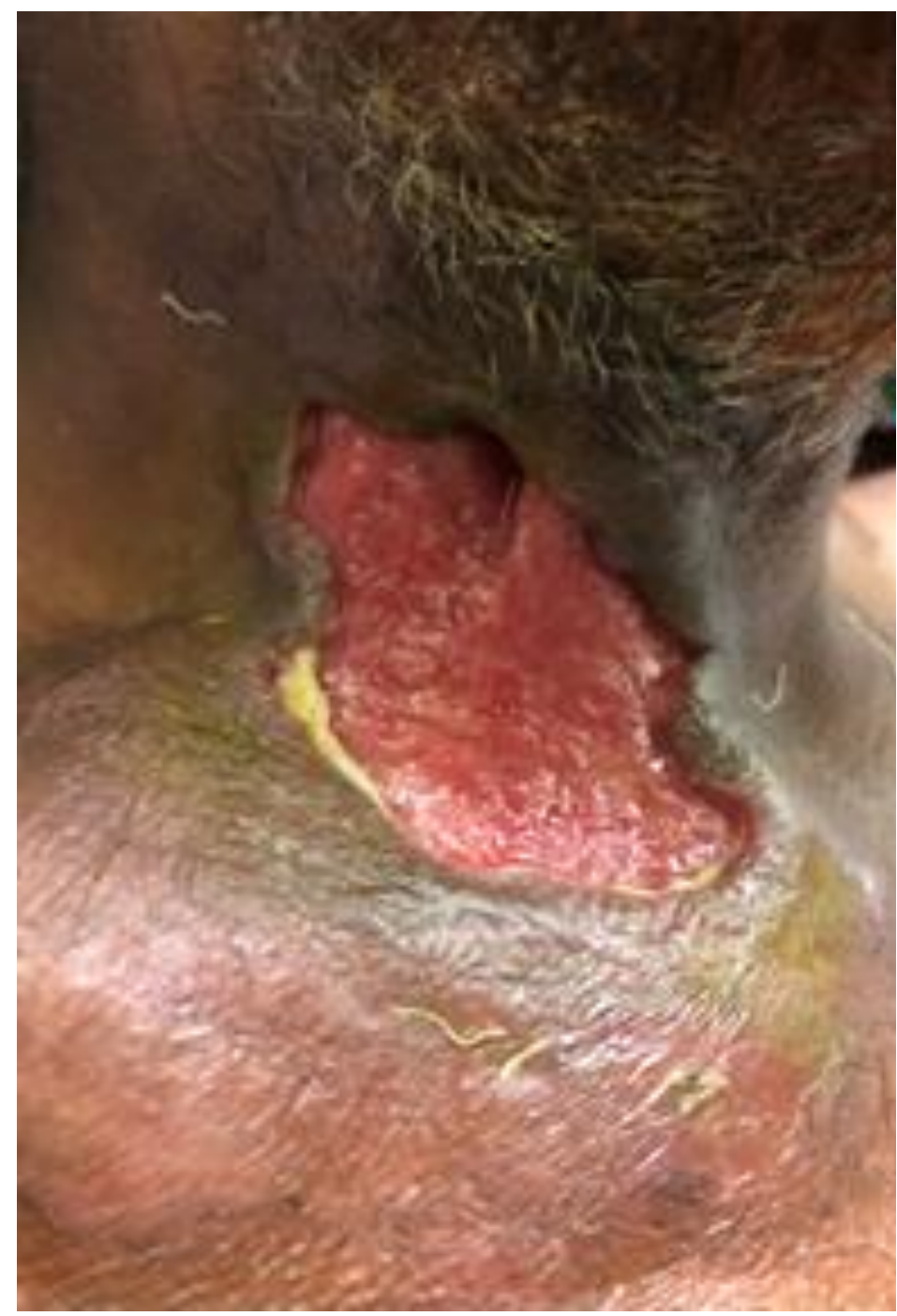

and regular antimicrobial socked dressings were done over next 10 days. Intra venous administration of ceftriaxone continued for three days followed by oral cefexime for seven days. Further spread of the lesion halted and margins started granulating and the patient's general condition improved. Healing of the wound occurred with secondary intention [Figure 2]. Regular follow up of the patient was done every month for next one year [Figure 3].

Figure 1: Soft tissue defect in the cervical region following aggressive debridement of the necrosed subcutaneous tissue and fascia.

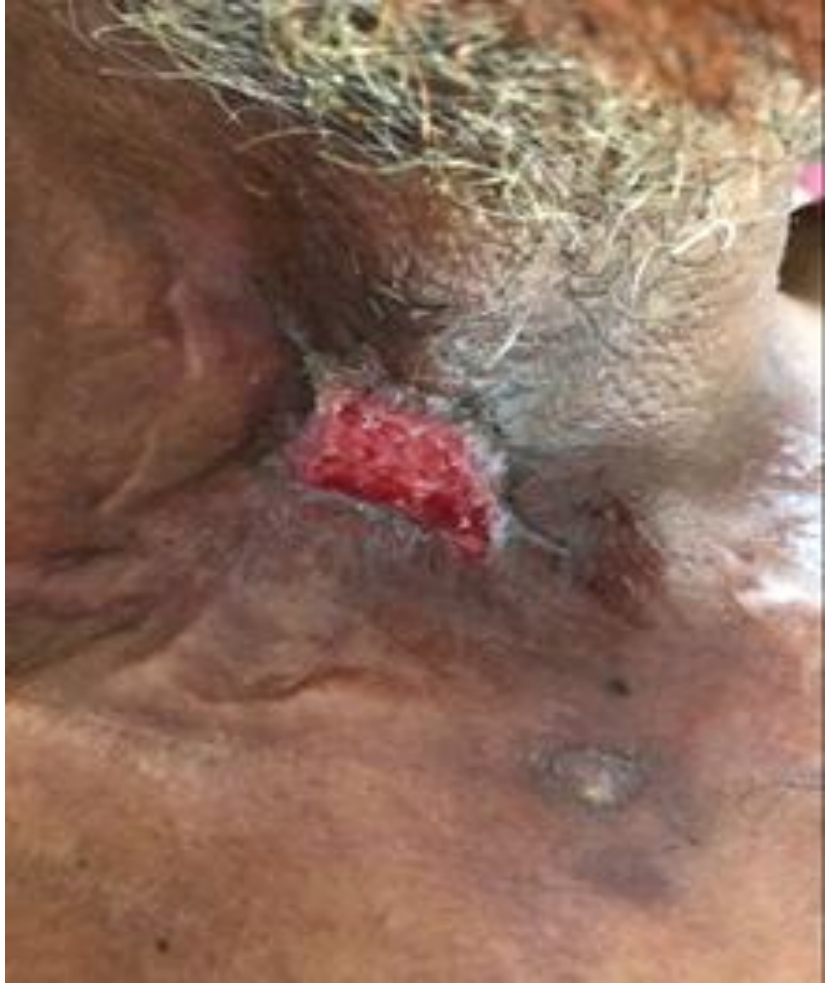

Figure 2: Healing of wound by secondary intention. 
Annals of International Medical and Dental Research E-ISSN: 2395-2822 | P-ISSN: 2395-2814 Vol-8, Issue-1 | January-February 2022 DOI: 10.53339/aimdr.2022.8.1.10 Page no- 69-80 | Section- Research Article (Oral \& Maxillofacial Surgery)

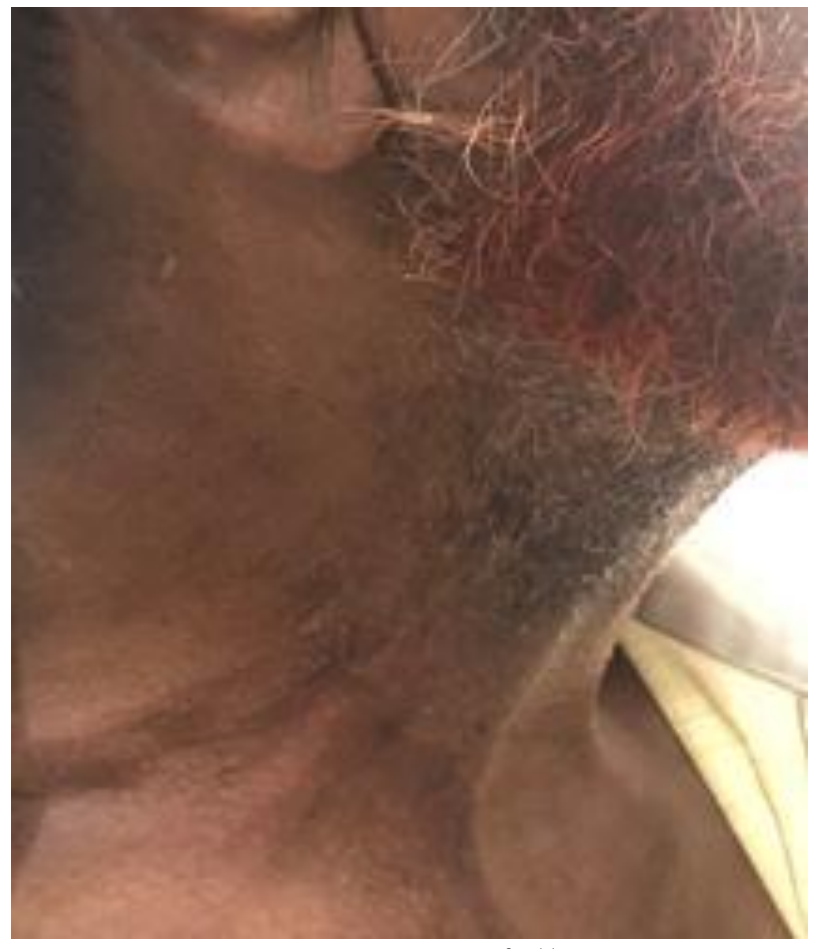

Figure 3: One year follow up.

\section{DISCUSSION}

\section{Literature review}

Rapoport in the year 1991 reported three cases of cervical necrotizing fasciitis originating from dental infections.[8] Banerjee et al in 1996 reported two cases and performed literature review and suggested that cervical necrotizing fasciitis and craniofacial necrotizing fasciitis are two distinct clinicopathological forms of head and neck necrotizing fasciitis. ${ }^{\text {[9] Debacker }}$ et al in the same year reported a case of cervical necrotizing fasciitis secondary to dental infection.[10]

Kantu and Har-El in the year 1997 presented a case series of 8 patients with cervical necrotizing fasciitis, out of which 6 patients had odontogenic infection.[11] Mohammedi et al in the year 1999 presented a retrospective study on 20 patients with cervical necrotizing fasciitis and concluded that early recognition and debridement is important for better prognosis. 12 ] Whitesides et al in the year 2000 reported a case and reviewed 12 cases of cervical necrotizing fasciitis of odontogenic infection origin and suggested early intervention and use of hyperbaric oxygen therapy in its management.[13] Wong et al in the same year presented a retrospective review of 11 cases of cervical necrotizing fasciitis of odontogenic origin. ${ }^{[14]}$ Bahu et al in the year 2001 conducted a retrospective review of 10 patients with craniocervical necrotizing fasciitis and found thoracic extension of infection in $50 \%$ of patients.[15] Lin et al in the same year analyzed 47 cases of necrotizing fasciitis of head and neck region and recommended early recognition, aggressive debridement, broad spectrum antibiotics and intensive care of the patients for better prognosis.[16]

Skitarelic et al in the year 2003 reported a case and reviewed 12 cases of cervical necrotizing fasciitis originating from peritonsillar abscesses and observed a higher mortality rate as compared to those arising from odontogenic infection.[1] Mora et al in the year 2004 described 21 cases of descending necrotizing mediastinitis following odontogenic or peritonsillar infection. [17]

Bilbault et al in 2008 reported a case of cervical necrotizing fasciitis following extraction of maxillary tooth. ${ }^{18]}$ Fihman et al in the study on 152 patients observed that Streptococcus milleri and Prevotella species were the most common microbes in cervical necrotizing fasciitis originating from dental infections. Penicillin and Clindamycin resistance was 
Annals of International Medical and Dental Research

E-ISSN: 2395-2822 | P-ISSN: 2395-2814

Vol-8, Issue-1 | January-February 2022

DOI: $10.53339 /$ aimdr.2022.8.1.10

Page no- 69-80 | Section- Research Article (Oral \& Maxillofacial Surgery)

observed independent of previous antibiotic therapy. ${ }^{19]}$ Flanagan et al in 2009 observed in a case series that adjunctive use of hyperbaric oxygen therapy in cervical necrotizing fasciitis reduce the overall hospital stay of the patients.[20] Ord and Colleti in the same year presented a review on cervical necrotizing fasciitis. [3]

Wolf et al in the year 2010 conducted a study on 17 patients with head and neck necrotizing fasciitis. [21] Bakshi et al in the same year conducted a retrospective review of 11 patients with cervical necrotizing fasciitis. They found that dental infection was the most common etiology. [5] Karkas et al presented a retrospective study on 17 patients with cervical necrotizing fasciitis associated with descending necrotizing mediastinitis.[22] Lanisnik and Cizmarevic in a retrospective study on 34 patients with head and neck necrotizing fasciitis further classified the disease into cervical and cranial types. [23] Lingraj et al in the same year reported a case of cervical necrotizing fasciitis and reviewed the literature.24] Malik et al in the same year reported five cases of cervical necrotizing fasciitis and suggested an algorithm for its early diagnosis.[25]

Maria and Rajnikanth reported a case of cervical necrotizing fasciitis due to dental infection. ${ }^{4]}$ Shaariyah et al also reported three cases of necrotizing fasciitis involving head and neck in the same year.[26]

Chung and Scott in 2012 reported two cases of cervical necrotizing fasciitis in children below two years of age.[27] Toro et al in 2014 reported six cases of cervical necrotizing fasciitis with oropharyngeal or odontogenic origin spreading to involve mediastinum caused by mixed flora of Prevotella, Peptostreptococcus and coagulase-negative Staphylococcus. [2]

Frankel et al in 2015 reported a case of management of cervical necrotizing fasciitis with the use of negative pressure wound therapy with instillation. $\underline{28]}$

Arruda et al in 2016 reported a case of cervical necrotizing fasciitis following extraction of mandibular lateral incisor in a geriatric patient. [7] Gore in 2018 presented a systematic review of literature on necrotizing fasciitis due to odontogenic infections and concluded diabetes mellitus as a significant risk factor. [29] Gunaratne et al in the same year presented a systematic review of 1235 cases of cervical necrotizing fasciitis.[30] Ferzli et al in 2019 reported cases of cervical necrotizing fasciitis and suggested the reconstruction of large defects with flaps. ${ }^{[6]}$ Chen et al reported a case series of patients with necrotizing fasciitis of head and neck region who were treated with negative pressure wound therapy.[31] Figueiredo et al in the same year reported a case of persistent necrotizing mediastinistis following a dental extraction.[32]

\section{Epidemiology}

The incidence of necrotizing fasciitis is 0.40 cases per 100,000 people. It can occur in all age groups but particularly common in individuals below 40 years of age. No sex predilection is observed. Necrotizing fasciitis most commonly involves abdominal wall, perineum and limbs. Less than 10 percent of total cases involve the cervicofacial region. [3] Wong et al reported an incidence of $2.6 \%$ of cervical necrotizing fasciitis among the patients who were admitted 
Annals of International Medical and Dental Research

E-ISSN: 2395-2822 | P-ISSN: 2395-2814

Vol-8, Issue-1 | January-February 2022

DOI: $10.53339 /$ aimdr.2022.8.1.10

Page no- 69-80 | Section- Research Article (Oral \& Maxillofacial Surgery)

for oral \& maxillofacial infections and described odontogenic infections as the most common causative factor. $[14]$ Incidence and case fatality rate of cervical necrotizing fasciitis is less in children as compared to adults. [27]

\section{Etiology}

Odontogenic infection is the most common precipitating event for cervical necrotizing fasciitis. Other causes are tonsillar abscesses, parotitis, otitis media, trauma, or surgery of the head and neck. Among odontogenic infection periapical periodontitis is the most common cause while involvement of lower molars is most commonly observed. $[13,14,33]$ Whitesides et al reported 12 cases of cervical necrotizing fasciitis in a retrospective review due to odontogenic origin, most commonly resulting from abscessed mandibular molars. [13] Skitarelic et al reviewed cases of cervical necrotizing fasciitis originating from peritonsillar abscess and found higher mortality rate in such cases due to spread of infection through deeper fascial planes.[1]

Melaney first described the classical association of Beta -haemolytic group A streptococci as most common pathogen involved in necrotizing fasciitis. However, necrotizing fasciitis is usually considered as polymicrobial infection having synergistic activity between aerobic and anaerobic bacteria. [3]

Giuliano et al in the year 1977 categorized necrotizing fasciitis broadly into Type I and Type II based on the bacteria responsible for the disease. Type I necrotizing fasciitis is a polymicrobial infection from aerobic and anaerobic bacteria such as Clostridium and
Bacteroides species while Type II necrotizing fasciitis consists of group A Streptococcus (S. pyogenes) with or without a coexisting Staphylococcal infection. The other microbes which may be involved in Type I are Eikenella, Peptococcus, Pseudomonas, Fusobacterium, Candida, Cryptococcus, Corynebacterium, Histoplasma, Streptococcus (not included in group A), Vibrio, Escherichia, Staphylococcus, Enterobacter, Shigella Proteus, Neisseria, Klebsiella, Pasturella, Serratia, Salmonella.[19,29,34]

Mc Gurk in 2003 categorized necrotizing fasciitis into three types. First category is seen in temperate climates where group A Streptococcus with or without Staphylococcus aureus are the main causative microbes. Second category includes polymicrobial infections due to aerobes and anaerobes where anaerobes like Peptostreptococcus, Prevotella, Porphyromonas, Bacteroides and Clostridia predominate and occur in up to $60 \%$ of cases. Third category is seen in tropical climates where the condition can be caused by members of the family Vibrionacae, which are of seawater origin. [35]

Lin et al described the role of Klebsiella pneumoniae besides Streptococci and Staphylococci in necrotizing fasciitis of the head \& neck region. ${ }^{16]}$ Lee et al suggested increasing incidence of methicillin resistant Staphylococcus aureus (MRSA) in causing necrotizing fasciitis and mentioned the need of prompt MRSA directed antibiotic therapy. [36] Tsai et al pointed towards increasing incidence of monomicrobial necrotizing fasciitis and higher mortality rates of gram- negative pathogens in the warm coastal areas. They also found that Vibrio vulnificus infection is more 
Annals of International Medical and Dental Research

E-ISSN: 2395-2822 | P-ISSN: 2395-2814

Vol-8, Issue-1 | January-February 2022

DOI: 10.53339 /aimdr.2022.8.1.10

Page no- 69-80 | Section- Research Article (Oral \& Maxillofacial Surgery)

rapidly progressing and fulminant than MRSA in causing necrotizing fasciitis. ${ }^{[37]}$ Hsiao et al in 2007 suggested that Aeromonas and Vibrio infection, cancer, hypotension and band form white blood cell count greater than $10 \%$ are independent positive predictors while presence of hemorrhagic bullae is an independent negative predictor of mortality in necrotizing fasciitis. [38]

\section{Predisposing factors}

Immuno-compromised individuals are more susceptible to necrotizing fasciitis as compared to healthy individuals. Incidence, morbidity and mortality of necrotizing fasciitis increases in patients suffering from diabetes mellitus, chronic renal failure, peripheral vascular disease, AIDS, liver cirrhosis, lymphomas/ leukemias, intra venous drug abuse, surgery, ischemic ulcers, obesity, malnutrition and alcoholism. Advanced age is also one of the risk factor. Patient undergoing chemo radiation therapy or taking steroids are at increased risk. $[3,7,15,33,39]$ Lack of specific antigens of group A streptococcus is also considered as predisposing factor for the development of necrotizing fasciitis. [21]

\section{Pathogenesis}

In the initial stage of the necrotizing fasciitis, liquefactive necrosis of the subcutaneous fat and fascia takes place by the action of collagenase and hyaluronidase produced by the group A Streptococci. Mucopeptides from the streptococcal cell wall may penetrate through dermal collagen and cause separation of fascial planes while bacterial lipase and hyaluronidase cause liquefaction necrosis of fat and fascia. Oedema separates the skin from the underlying tissue. Pathognomic foul smelling dish water pus mostly occur due to the presence of anaerobes. Thrombosis of the perforating veins supplying the skin blocks the venous return from the skin causing increased oedema and purplish mottling of the skin. Skin surrounding the infected area becomes erythematous as a result of inflammatory response with dense infiltrate of polymorphonuclear cells migrating into the surrounding subcutaneous tissue. As the necrotic process progresses, arterial thrombosis takes place which devitalize the skin which turns pale, purple and finally black. This makes the overlying skin anaesthetic. Skin may eventually slough exposing the underlying muscles. In case myositis pursues exposure of the underlying bones may occur. [3,11]

\section{Diagnosis}

Necrotizing fasciitis is characterized by rapid progression and fatal outcome if not diagnosed and treated early in the course. Rate of necrosis is disproportionate to clinical signs and symptoms making early diagnosis a challenging work. The disease in its early phase is clinically indistinguishable from cellulitis, erysipelas and other soft tissue infections. Erysipelas classically involves the skin and lymphatics, cellulitis affect the subcutaneous tissue while necrotizing fasciitis classically involves subcutaneous fat and fascia with sparing of skin and muscles in the initial stages of the disease. $[2,4,5]$

Wang et al suggested a clinical staging of the disease progression based on cutaneous signs. Tenderness to palpation, erythema, swelling and calor are the signs corresponding to the stage I. Appearance of blisters and bullae 
Annals of International Medical and Dental Research E-ISSN: 2395-2822 | P-ISSN: 2395-2814 Vol-8, Issue-1 | January-February 2022 DOI: $10.53339 /$ aimdr.2022.8.1.10 Page no- 69-80 | Section- Research Article (Oral \& Maxillofacial Surgery)

formation with serous fluid discharge makes the intermediate or $2^{\text {nd }}$ stage. Presence of crepitus, skin anaesthesia, skin necrosis with dusky discoloration are the late signs suggestive of stage III.[40]

Clinical presentation of inelastic oedema, cyanosis, pallor and hypoesthesia of skin, foul smelling dishwater exudate and rapid progression indicates towards the diagnosis of necrotizing fasciitis. Toxic appearance, fever, chills, decreased urinary output, weakness, fatigue, altered mental status, tachycardia, tachypnea, leukocytosis, hypocalcemia and metabolic acidosis which are usual manifestations of systemic infection help in diagnosis. Shock, multiple organ failure and even death may pursue if not treated early. [7,41]

Complete blood count may show elevated white blood cell count. However leukocyte count is less helpful in diagnosis. Normochromic normocytic anaemia may also be present. Raised serum urea and glucose levels may also be observed. Elevated erythrocyte sedimentation rate, elevated aldolase and hypocalcaemia may also be present. Serum C reactive protein levels are raised. Increased serum creatinine levels are indicative of myositis or myonecrosis or ischemia. Serum creatinine kinase levels of $600 \mathrm{U} / \mathrm{L}$ or more raises the suspicion of necrotizing fasciitis. In-oxine labelled leukocyte imaging has also been identified as a useful tool in the early diagnosis of cervical necrotizing fasciitis. Gram staining and culture and sensitivity tests help in starting a directed antibiotic therapy. [41,42,43]

Radiographic examination of the region may show presence of subcutaneous gas.
Ultrasonographic examination is economic, non-invasive investigation with good sensitivity and specificity. Contrast enhanced computerized tomographic examination of the cervical region may show diffuse thickening and enhancement of the subcutaneous tissue, diffuse enhancement of the superficial or/and deep fascia and the adjoining muscles like platysma, sternocleidomastoid and strap muscles. Presence of subcutaneous gas is seen in $55 \%$ to $64 \%$ of the cases. Abscess formation, mediastinal widening, gas tracking, empyema, pleural and pericardial effusions are signs of thoracic extension. $[3,15]$ Culture independent and rapid identification of bacterial pathogens in necrotizing fasciitis can be done by fluorescence in situ hybridisation (FISH). [44] Fine needle aspiration, fascial biopsy, and surgical exploration followed by histopathological examination make more accurate diagnosis of necrotizing fasciitis. [45]

\section{Management}

Management is broadly categorized into five steps. First step is the resuscitation of the systemically ill patient. Intravenous fluid should be administered in patient with septic shock and electrolyte imbalance should be corrected in patients with renal failure. Patient's airway need to be evaluated and if needed intubation or tracheotomy should be done without delay. Empirical antibiotic therapy should be started till the reports of the culture and sensitivity test are available. $[4,5]$

Second step is aggressive surgical debridement. Bioavailability of the drugs is reduced in the ischemic and necrotic tissues which make early debridement of necrotic tissue vital for better prognosis. As the patient 
Annals of International Medical and Dental Research E-ISSN: 2395-2822 | P-ISSN: 2395-2814 Vol-8, Issue-1 | January-February 2022 DOI: $10.53339 /$ aimdr.2022.8.1.10 Page no- 69-80 | Section- Research Article (Oral \& Maxillofacial Surgery)

stabilises, immediate surgical debridement of all the necrotic fascia and subcutaneous tissue along with overlying necrotic skin and adjoining necrotic muscles should be done. A wide apron incision is recommended for access to all cervical regions. The area of the dead skin is greater than perceived clinically and can best be delineated by cutting back the skin that is dissected easily by finger pressure until the edges bleed. Nerves should be spared if intact. At this stage wound should be packed open because early closure increase the risk of infection and poor wound healing. Local muscle flaps can be used if vital structures like carotid artery are exposed. Secondary suturing, shoe lace technique and skin grafting are other alternative techniques. In case of anaerobic infection gauze socked in normal saline with dilute hypochlorite can be used. Povidine iodine gauze can also be used. Irrigation with dilute acetic acid is recommended in case of Pseudomonal infection. Repeated debridement of the necrotic tissue is done till the wound is stabilized. Alloderm is used for temporary dressing over extensive wound. $[5,7,15]$

Third step is targeted antibiotic therapy. Mortality rate of necrotizing fasciitis was more than $50 \%$ in the pre antibiotic era. Mortality rate remained unexpectedly high even after the advent of intravenous antibiotics. Mortality rate was reported to be $36 \%$ between 1960 and 1980, 33\% between 1980 and 1990 and now reduced to $10 \%$ to $15 \%$ in the recent studies. Antibiotic coverage based on culture and sensitivity tests targeting gram positive, gram negative and anaerobic bacteria is recommended. Dosing of renal excreting antimicrobials needs to be adjusted as acute renal failure is the commonly observed in severe infection. $[2,7,15]$

Fourth step is the intensive care and support. Supportive care in the intensive care unit involves fluid resuscitation, cardiac monitoring and adequate nutritional support which is vital for patient's survival.44,5] Hypokalemia may result secondary to extensive tissue damage and fluid loss which can lead to cardiac arrhythmias, so maintaining electrolyte balance is vital. The hemoglobin level should be kept above $10 \mathrm{~g} / \mathrm{dl}$ and the serum protein level above $5 \mathrm{~g} / \mathrm{dl}$ to promote rapid wound healing in such patients. []

Hyperbaric oxygen (HBO) therapy is an adjunctive therapy in which partial pressure of oxygen is increased up to four times, thereby increasing the bactericidal action of neutrophils, as high oxygen tension increase the efficiency of peroxide-dependent killing by neutrophils. Hyperbaric oxygen therapy promotes angiogenesis, improve vascularization which help in increasing penetration of neutrophils, macrophages and antibiotics to the affected area. Various studies have shown conflicting results for the effectiveness of $\mathrm{HBO}$ therapy in cervical necrotizing fasciitis management. $[7,15,20]$

Once the necrotizing process is halted with surgical debridement and medical management, negative pressure wound therapy or vacuum-assisted closure dressing with a continuous pressure of $40-100 \mathrm{mmHg}$ is useful for wound coverage and encourages granulation before and after skin grafting. However its use in acute infection is to be avoided. $[7,28]$ Negative pressure wound therapy helps in controlling tissue oedema, improves 
Annals of International Medical and Dental Research

E-ISSN: 2395-2822 | P-ISSN: 2395-2814

Vol-8, Issue-1 | January-February 2022

DOI: $10.53339 /$ aimdr.2022.8.1.10

Page no- 69-80 | Section- Research Article (Oral \& Maxillofacial Surgery)

perfusion, prevents bacterial colonization and enhance angiogenesis leading to faster granulation tissue growth. This therapy involves the use of special sponge or gauge along with vacuum device with a well sealed wound site.[46] Argenta and Morykwas introduced vacuum assisted closure device (VAC) used in negative pressure wound therapy.[31] Intravenous immunoglobulins may also play a role in treating necrotizing fasciitis as it is shown to be effective in treating patients with Streptococcal toxic shock syndrome (STTS) by neutralizing the superantigens involved.[1]

Final step is the reconstruction of the large defects. Reconstructive surgery should be considered only after the patient has been stabilized and the infection fully eradicated. In case of large defects, vascularized graft may be considered like regional rotational (eg, pectoralis major, latissimus dorsi, or trapezius) or free flaps (eg, radial forearm, anterolateral thigh, or scapular). [6]

\section{Complications}

Systemic spread of the infection may result in complications like acute renal failure, adult respiratory distress syndrome, disseminated intravascular coagulation, electrolyte

\section{REFERENCES}

1. Skitarelić N, Mladina R, Morović M, Skitarelić N. Cervical necrotizing fasciitis: sources and outcomes. Infection. 2003;31(1):39-44. doi: 10.1007/s15010-002-3057-2.

2. Cruz Toro P, Callejo Castillo À, Tornero Saltó J, González Compta X, Farré A, Maños M. Cervical necrotizing fasciitis: report of 6 cases and review of literature. Eur Ann Otorhinolaryngol Head Neck Dis. 2014;131(6):357359. doi: 10.1016/j.anorl.2013.08.006. abnormalities, pneumonia, gastrointestinal bleeding and nephropathy. Local wound healing complications like hemorrhage, hematoma and pharygocutaneous fistula can occur. Thoracic complications of the cervical necrotizing fasciitis include mediastinitis, pericarditis, pleural effusion, empyema, pericardial effusion, pneumonitis, cardiac tamponade and esophageal bleed. Infection either spreads from submandibular space to parapharyngeal space through carotid sheath into mediastinum or infection may spread through retropharyngeal or prevertebral space into the posterior mediastinum. If the infection spreads from paratracheal region to the level of tracheal bifurcation, where the middle layer of deep cervical fascia fuse with parietal pericardium and adventitia of great vessels and also is closely adhered to mediastinal parietal pleura making a pathway for the spread of infection in pericardial and pleural cavities. [15]

\section{CONCLUSION}

Cervical necrotizing fasciitis is a rare fulminant infection with high mortality rate. Early identification, aggressive surgical debridement, broad spectrum followed by targeted antibiotic therapy and intensive care is vital for better prognosis.

3. Ord R, Coletti D. Cervico-facial necrotizing fasciitis. Oral Dis. 2009;15(2):133-41. doi: 10.1111/j.16010825.2008.01496.x.

4. Maria A, Rajnikanth K. Cervical necrotizing fasciitis caused by dental infection: A review and case report. Natl J Maxillofac Surg. 2010;1(2):135-8. doi: 10.4103/09755950.79215.

5. Bakshi J, Virk RS, Jain A, Verma M. Cervical necrotizing fasciitis: Our experience with 11 cases and our technique 
Annals of International Medical and Dental Research

E-ISSN: 2395-2822 | P-ISSN: 2395-2814

Vol-8, Issue-1 | January-February 2022

DOI: $10.53339 /$ aimdr.2022.8.1.10

Page no- 69-80 | Section- Research Article (Oral \& Maxillofacial Surgery)

for surgical debridement. Ear Nose Throat J. 2010;89(2):84-6.

6. Ferzli G, Sukato DC, Mourad M, Kadakia S, Gordin EA, Ducic Y. Aggressive Necrotizing Fasciitis of the Head and Neck Resulting in Massive Defects. Ear Nose Throat J. 2019;98(4):197-200. doi: 10.1177/0145561319839789.

7. Arruda JA, Figueiredo E, Álvares P, Silva L, Silva L, Caubi A, Silveira M, Sobral AP. Cervical Necrotizing Fasciitis Caused by Dental Extraction. Case Rep Dent. 2016;2016:1674153. doi: 10.1155/2016/1674153.

8. Rapoport Y, Himelfarb MZ, Zikk D, Bloom J. Cervical necrotizing fasciitis of odontogenic origin. Oral Surg Oral Med Oral Pathol. 1991;72(1):15-8. doi: 10.1016/00304220(91)90181-b.

9. Banerjee AR, Murty GE, Moir AA. Cervical necrotizing fasciitis: a distinct clinicopathological entity? J Laryngol Otol. 1996;110(1):81-6. doi: 10.1017/s0022215100132797.

10. De Backer T, Bossuyt M, Schoenaers J. Management of necrotizing fasciitis in the neck. J Craniomaxillofac Surg. 1996;24(6):366-71. doi: 10.1016/s1010-5182(96)80038-2.

11. Kantu S, Har-El G. Cervical necrotizing fasciitis. Ann Otol Rhinol Laryngol. 1997;106(11):965-70. doi: 10.1177/000348949710601113.

12. Mohammedi I, Ceruse P, Duperret S, Vedrinne J, Boulétreau P. Cervical necrotizing fasciitis: 10 years' experience at a single institution. Intensive Care Med. 1999;25(8):829-34. doi: 10.1007/s001340050959.

13. Whitesides L, Cotto-Cumba C, Myers RA. Cervical necrotizing fasciitis of odontogenic origin: a case report and review of 12 cases. J Oral Maxillofac Surg. 2000;58(2):144-51. doi: 10.1016/s0278-2391(00)90327-6.

14. Tung-Yiu W, Jehn-Shyun H, Ching-Hung C, Hung-An C. Cervical necrotizing fasciitis of odontogenic origin: a report of 11 cases. J Oral Maxillofac Surg. 2000;58(12):1347-52. doi: 10.1053/joms.2000.18259.

15. Bahu SJ, Shibuya TY, Meleca RJ, Mathog RH, Yoo GH, Stachler RJ, et al. Craniocervical necrotizing fasciitis: an 11-year experience. Otolaryngol Head Neck Surg. 2001;125(3):245-52. doi: 10.1067/mhn.2001.118182.

16. Lin C, Yeh FL, Lin JT, Ma H, Hwang CH, Shen BH, et al. Necrotizing fasciitis of the head and neck: an analysis of 47 cases. Plast Reconstr Surg. 2001;107(7):1684-93. doi: 10.1097/00006534-200106000-00008.

17. Mora R, Jankowska B, Catrambone U, Passali GC, Mora $\mathrm{F}$, Leoncini $\mathrm{G}$, et al. Descending necrotizing mediastinitis: ten years' experience. Ear Nose Throat J. 2004;83(11):774, 776-80.

18. Bilbault P, Castelain V, Schenck-Dhif M, Schneider F, Charpiot A. Life-threatening cervical necrotizing fasciitis after a common dental extraction. Am J Emerg Med. 2008;26(8):971.e5-7. doi: 10.1016/j.ajem.2008.01.053.

19. Fihman V, Raskine L, Petitpas F, Mateo J, Kania R, Gravisse J, et al. Cervical necrotizing fasciitis: 8-years' experience of microbiology. Eur J Clin Microbiol Infect Dis. 2008;27(8):691-5. doi: 10.1007/s10096-008-0491-9.

20. Flanagan CE, Daramola OO, Maisel RH, Adkinson C, Odland RM. Surgical debridement and adjunctive hyperbaric oxygen in cervical necrotizing fasciitis. Otolaryngol Head Neck Surg. 2009;140(5):730-4. doi: 10.1016/j.otohns.2009.01.014.

21. Wolf H, Rusan M, Lambertsen K, Ovesen T. Necrotizing fasciitis of the head and neck. Head Neck. 2010;32(12):1592-6. doi: 10.1002/hed.21367.

22. Karkas A, Chahine K, Schmerber S, Brichon PY, Righini CA. Optimal treatment of cervical necrotizing fasciitis associated with descending necrotizing mediastinitis. Br J Surg. 2010;97(4):609-15. doi: 10.1002/bjs.6935.

23. Lanisnik B, Cizmarevic B. Necrotizing fasciitis of the head and neck: 34 cases of a single institution experience. Eur Arch Otorhinolaryngol. 2010;267(3):415-21. doi: 10.1007/s00405-009-1007-7.

24. Lingaraj JB, Rao S, Kotrashetti SM, Narad C. Necrotizing cervical fasciitis: a case report and review of literature. J Maxillofac Oral Surg. 2010;9(1):54-6. doi: 10.1007/s12663010-0015-x.

25. Malik V, Gadepalli C, Agrawal S, Inkster C, Lobo C. An algorithm for early diagnosis of cervicofacial necrotising fasciitis. Eur Arch Otorhinolaryngol. 2010;267(8):1169-77. doi: 10.1007/s00405-010-1248-5.

26. Ikram M, Saeed O, Ali SS, Salahuddin I. Necrotizing fasciitis of head \& neck: the Pakistani experience. Asian J Surg. 2002;25(1):13-7.

27. Chung V, Scott A. Cervical necrotizing fasciitis in children under two years of age. Int J Pediatr Otorhinolaryngol. 2012;76(12):1857-60. doi: 10.1016/j.ijporl.2012.09.012.

28. Frankel JK, Rezaee RP, Harvey DJ, McBeath ER, Zender CA, Lavertu P. Use of negative pressure wound therapy with instillation in the management of cervical necrotizing fasciitis. Head Neck. 2015;37(11):E157-60. doi: 10.1002/hed.24028.

29. Gore MR. Odontogenic necrotizing fasciitis: a systematic review of the literature. BMC Ear Nose Throat Disord. 2018;18:14. doi:10.1186/s12901-018-0059-y

30. Gunaratne DA, Tseros EA, Hasan Z, Kudpaje AS, Suruliraj A, Smith MC, et al. Cervical necrotizing fasciitis: Systematic review and analysis of 1235 reported cases from the literature. Head Neck. 2018;40(9):2094-2102. doi: 10.1002/hed.25184.

31. Chen SJ, Chen YX, Xiao JR, Wei XZ, Chen SM, Jiang WZ. Negative Pressure Wound Therapy in Necrotizing Fasciitis of the Head and Neck. J Oral Maxillofac Surg. 2019;77(1):87-92. doi: 10.1016/j.joms.2018.08.016.

32. Figueiredo EL, Aires CCG, Neres BJCM, Araujo BL, Arruda JAA, Vasconcellos RJH. Persistent necrotizing 
Annals of International Medical and Dental Research

E-ISSN: 2395-2822 | P-ISSN: 2395-2814

Vol-8, Issue-1 | January-February 2022

DOI: 10.53339 /aimdr.2022.8.1.10

Page no- 69-80 | Section- Research Article (Oral \& Maxillofacial Surgery)

mediastinitis after Dental Extraction. Case Rep Dent. 2019; 2019:6468348.

33. Qu L, Liang X, Jiang B, Qian W, Zhang W, Cai X. Risk Factors Affecting the Prognosis of Descending Necrotizing Mediastinitis From Odontogenic Infection. J Oral Maxillofac Surg. 2018;76(6):1207-1215. doi: 10.1016/j.joms.2017.12.007.

34. Giuliano A, Lewis F Jr, Hadley K, Blaisdell FW. Bacteriology of necrotizing fasciitis. Am J Surg. 1977;134(1):52-7. doi: 10.1016/0002-9610(77)90283-5.

35. McGurk M. Diagnosis and treatment of necrotizing fasciitis in the head and neck region. Oral Maxillofac Surg Clin North Am. 2003;15(1):59-67. doi: 10.1016/s10423699(02)00083-3.

36. Lee TC, Carrick MM, Scott BG, Hodges JC, Pham HQ. Incidence and clinical characteristics of methicillinresistant Staphylococcus aureus necrotizing fasciitis in a large urban hospital. Am J Surg. 2007;194(6):809-12. doi: 10.1016/j.amjsurg.2007.08.047.

37. Tsai YH, Huang TY, Chen JL, Hsiao CT, Kuo LT, Huang $\mathrm{KC}$. Bacteriology and mortality of necrotizing fasciitis in a tertiary coastal hospital with comparing risk indicators of methicillin-resistant Staphylococcus aureus and Vibrio vulnificus infections: a prospective study. BMC Infect Dis. 2021;21(1):771. doi: 10.1186/s12879-021-06518-5.

38. Hsiao CT, Weng HH, Yuan YD, Chen CT, Chen IC. Predictors of mortality in patients with necrotizing fasciitis. Am J Emerg Med. 2008;26(2):170-5. doi: 10.1016/j.ajem.2007.04.023.

39. McHenry CR, Piotrowski JJ, Petrinic D, Malangoni MA. Determinants of mortality for necrotizing soft-tissue infections. Ann Surg. 1995;221(5):558-565. doi:10.1097/00000658-199505000-00013
40. Wang YS, Wong CH, Tay YK. Staging of necrotizing fasciitis based on the evolving cutaneous features. Int J Dermatol. 2007;46(10):1036-41. doi: 10.1111/j.13654632.2007.03201.x.

41. Trent JT, Kirsner RS. Diagnosing necrotizing fasciitis. Adv Skin Wound Care. 2002;15(3):135-8. doi: 10.1097/00129334-200205000-00010.

42. Simonart T, Simonart JM, Derdelinckx I, De Dobbeleer G, Verleysen A, et al. Value of standard laboratory tests for the early recognition of group A beta-hemolytic streptococcal necrotizing fasciitis. Clin Infect Dis. 2001;32(1):E9-12. doi: 10.1086/317525.

43. Thomas AJ, Meyer TK. Retrospective evaluation of laboratory-based diagnostic tools for cervical necrotizing fasciitis. Laryngoscope. 2012;122(12):2683-7. doi: 10.1002/lary.23680.

44. Trebesius K, Leitritz L, Adler K, Schubert S, Autenrieth IB, Heesemann J. Culture independent and rapid identification of bacterial pathogens in necrotising fasciitis and streptococcal toxic shock syndrome by fluorescence in situ hybridisation. Med Microbiol Immunol. 2000;188(4):169-75. doi: 10.1007/s004300000035.

45. Majeski J, Majeski E. Necrotizing fasciitis: improved survival with early recognition by tissue biopsy and aggressive surgical treatment. South Med J. 1997;90(11):1065-8. doi: 10.1097/00007611-19971100000001.

46. Huang WS, Hsieh SC, Hsieh CS, Schoung JY, Huang T. Use of vacuum-assisted wound closure to manage limb wounds in patients suffering from acute necrotizing fasciitis. Asian J Surg. 2006;29(3):135-9. doi: 10.1016/S1015-9584(09)60072-5.

Source of Support: Nil, Conflict of Interest: None declared 